Dhaka Univ. J. Biol. Sci. 23(1): 17-26, 2014 (January)

\title{
DIVERSITY OF MOSQUITOES AND THEIR SEASONAL FLUCTUATION IN TWO WARDS OF DHAKA CITY
}

\author{
Humayun Reza Khan, Md. Muzahidul Islam, Tangin Akter, \\ MD. ReZAUl KARIM AND MD. SHEIK FARID \\ Department of Zoology, University of Dhaka, Dhaka-1000, Bangladesh
}

Key words: Diversity, Mosquitoes, Seasonal flucturation

\begin{abstract}
The diversity and seasonal fluctuation of mosquitoes were studied in the two Wards (No. 53 and 54) of Dhaka City from March, 2011 to February, 2012. Eleven habitats under six spots, viz. Ramna Park, Hatir Jheel, Siddeshwary field, Moghbazar pond, Wireless lane and Indoor habitats were surveyed. Altogether 13 species of mosquitoes were identified belonging to four genera and these were Culex quinquefasciatus, $C x$. gelidus, $C x$. vishnui, $C x$. fuscocephala, $C x$. tritaeniorhynchus, Cx. hutchinsoni, Cx. fatigans, Mansonia annulifera, Mn. uniformis, Mn. indiana, Aedes aegypti, Ae. Albopictus and Armigeres subalbatus. Seven species, e.g. Cx. gelidus, Cx. vishnui, Ae. aegypti, Ae. albopictus, Mn. uniformis, Mn. annulifera and $M n$. indiana were dominant in the months from June to October; three species, e.g. Cx. fuscocephala, Cx. quinquefasciatus and Ae. aegypti from November to February; and nine species, e.g. Ae. aegypti, Ae. albopictus, Ar. subalbatus, Cx. fuscocephala, Cx. gelidus, Cx. quinquefasciatus, Cx. tritaeniorhynchus, Cx. vishnui and $M n$. annulifera from March to May. Cx. quinquefasciatus was present in all habitats except the fresh water lake. In semi-polluted Jheel, all the mosquito species, except Ae. aegypti, Ae. albopictus and Mn. indiana were observed. In coconut shell, larvae belonging to $C x$. quinquefasciatus, Cx. fuscocephala, Ae. aegypti and $A r$. subalbatus were observed. In tree holes, Ae. albopictus occupied the highest number. In tubs, Cx. quinquefasciatus, Cx. vishnui, Ae. aegypti and Ae. albopictus were found. In polluted drains, $C x$. quinquefasciatus, $C x$. vishnui and $C x$. gelidus were common, but $C x$. quinquefasciatus was the dominant one. In indoor habitat, $C x$. quinquefasciatus and Ae. aegypti were more abundant.
\end{abstract}

\section{Introduction}

Mosquitoes are the most important single group of insects with regard to public health. They are remarkably adaptable and fully cosmopolitan, but predominantly tropical insect ${ }^{(1)}$. In Bangladesh, altogether 117 species of mosquitoes, including 36 anopheline, 79 culicine and two toxorhynchitine have so far been recorded $(2,3)$. Mosquitoes are the most important vectors of pathogenic organisms. Mosquito borne diseases include Malaria, West Nile Virus, Elephantiasis, Dengue fever, Chikungunya fever, Japanese encephalitis, Yellow fever etc. ${ }^{(4)}$ 
Dengue fever is acquired through the bite of Aedes aegypti and Ae. albopictus mosquitoes, both of which are present in Dhaka City. The first outbreak of dengue in Bangladesh was diagnosed in 1964 in Dhaka ${ }^{(5)}$. At present dengue hemorrhagic fever is common in Bangladesh(6). Human filariasis is caused by the parasite Wuchereria bancrofti and Brugia malayi which are transmitted by Mansonia, Aedes, Anopheles and Culex species. It has been suggested that Japanese encephalitis virus is an emerging cause of encephalitis in Bangladesh(7). Aedes and Culex appear to be the most important vectors of this disease ${ }^{(8)}$. Chikungunya fever is an acute febrile illness caused by an arthropod-borne alpha virus. In Bangladesh the first outbreak of Chikungunya disease was observed in 2008(9). The larval survey showed that predominant mosquito species in the outbreak areas was Ae. Albopictus. In Dhaka City, malaria disease is under control apparently due to the absence of mosquito vector, Anopheles species.

Many mosquito species change their habitats, behavior and vectoral capacity, and some species acquire resistance against insecticides. It is, therefore, essential to have knowledge about the abundance, seasonal variation and species composition of mosquitoes in the given area so as to perform and evaluate an effective mosquito control program $^{(10)}$. The objectives of the present study were to know the composition, seasonal population dynamics and habitat diversity patterns of the mosquito population in two wards of Dhaka City.

\section{Materials and Methods}

Both adults and larvae of the mosquitoes of Dhaka City were surveyed from March, 2011 to February, 2012. They were collected from six spots of wards No. 53 and 54 of Dhaka City. The spots, from which the larvae were collected, were Ramna Park (A), Hatir Jheel (B), Siddeswary Field (C), Moghbazar Pond (D), Wireless Lane (E) and Indoor habitat (F). Ramna Park was divided into four sub-spots, e.g. fresh water lake (A-1), tin container (A-2), tub (A-3) and tree hole (A-4) (Fig. 1).

The mosquito larvae were collected with the aid of a dipping net and a semi round disc. The method of collection was based on the classical dipping method with a piece of gauze mounted on a circular frame $(10 \mathrm{~cm}$ diameter $)$ attached to a rod like handle $(1 \mathrm{~m}$ long). The net had been drawn through water until it became clogged with particles and sludge. It was then removed from the water and emptied into a large white tray $(30 \times 22 \times$ $4 \mathrm{~cm}$ ). Different larval instars of the mosquito were sorted out with the help of a pipette. The larvae were collected from different habitats and transferred into rearing cases in the laboratory for the emergence of adults. Some of the larvae were preserved in $70 \%$ alcohol for identification. The newly emerged adult mosquito was killed by using chloroform and preserved in a small size plastic pod for identification.

The adult species were collected by a sweeping net and also by following the spray sheet technique. The sweeping net was used for adult mosquito collection from its 
breeding, resting, flying and feeding habitats. In every ten minutes, the sweeping net was swept ten times to collect the mosquito species. Then the collected specimens were anesthetized with chloroform soaked in a cotton ball in a jar. The collected specimens were preserved into separate plastic boxes. Then, the plastic boxes were properly labeled with habitat, date and time, and brought to the Entomology Laboratory, Department of Zoology, Dhaka University. A white spray sheet was used to collect the adult mosquitoes being knockdown and killed by aerosol spray. The length and breadth of a white spray sheet were 2 and $1.2 \mathrm{~m}$, respectively. At each room, four spray sheets were used for adult collection. Aerosols were sprayed for one minute. The white spray sheet was laid down on the floor of the room previously. The rooms were sprayed with aerosol thoroughly covering ceiling area and under tables, chairs, beds etc. and closed the door for $10-15$ minutes. The sheets were removed one by one with the dead adult mosquitoes. Then the mosquitoes were collected using an aspirator and forceps or direct inclusion from spray sheet to plastic boxes. All the larval and adult mosquitoes were identified under a stereoscopic binocular microscope following the taxonomic key of Barracuda ${ }^{(11)}$.

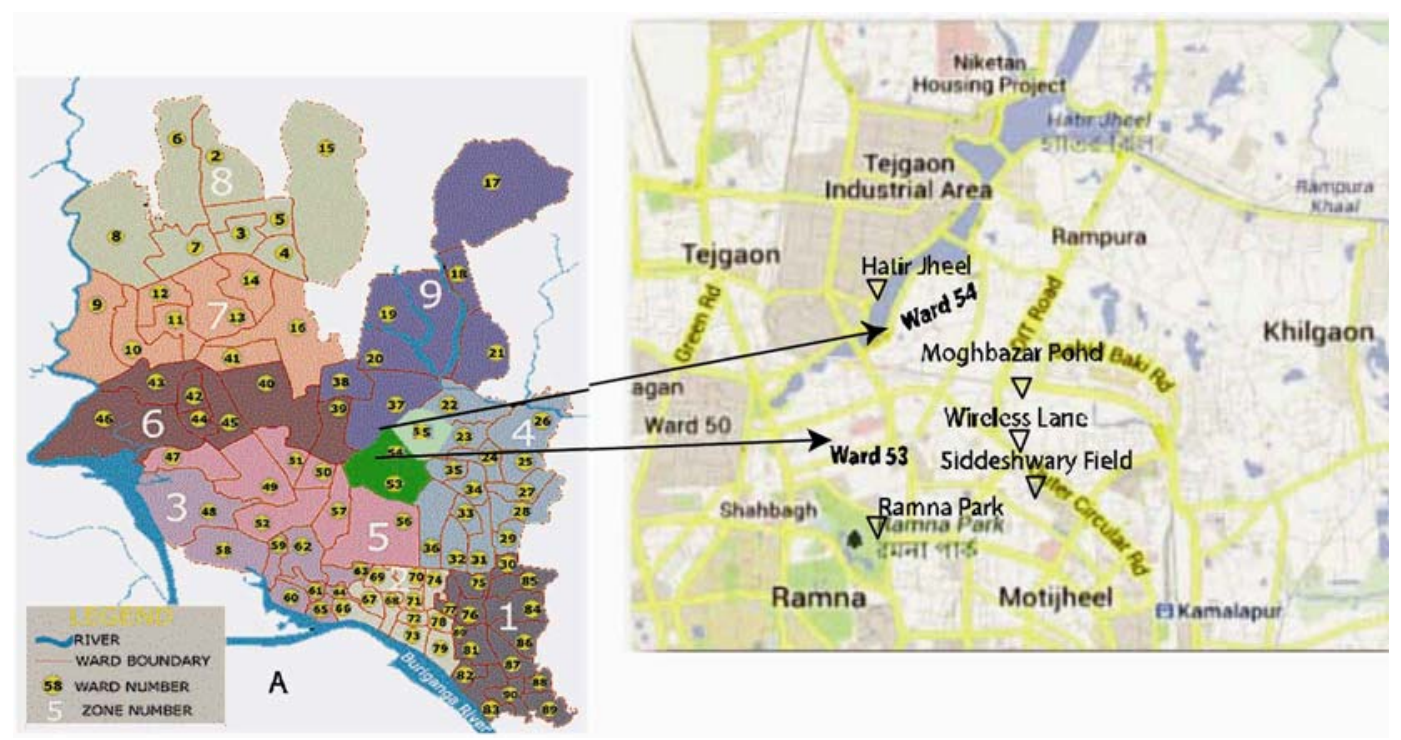

Fig. 1. Study areas: A. Map of Dhaka Metropolitan City. B. Location of wards 53 and 54.

\section{Results and Discussion}

A total number of 3299 samples of 13 species under three genera were collected, out of which seven belonged to the genus Culex, three to Mansonia, two to Aedes and one to Armigeres. The species were Culex quinquefasciatus, $C x$. vishnui, $C x$. gelidus, $C x$. tritaeniorhynchus, Cx. fuscocephala, Cx. fatigans, Cx. hutchinsoni, Mansonia uniformis, Mn. annulifera, Mn. indiana, Aedes aegypti, Ae. albopictus and Armigeres subalbatus (Table 1). In 1973, 27 species of mosquitoes were recorded in Dhaka City, out of which eight belonged 
KHAN et al.

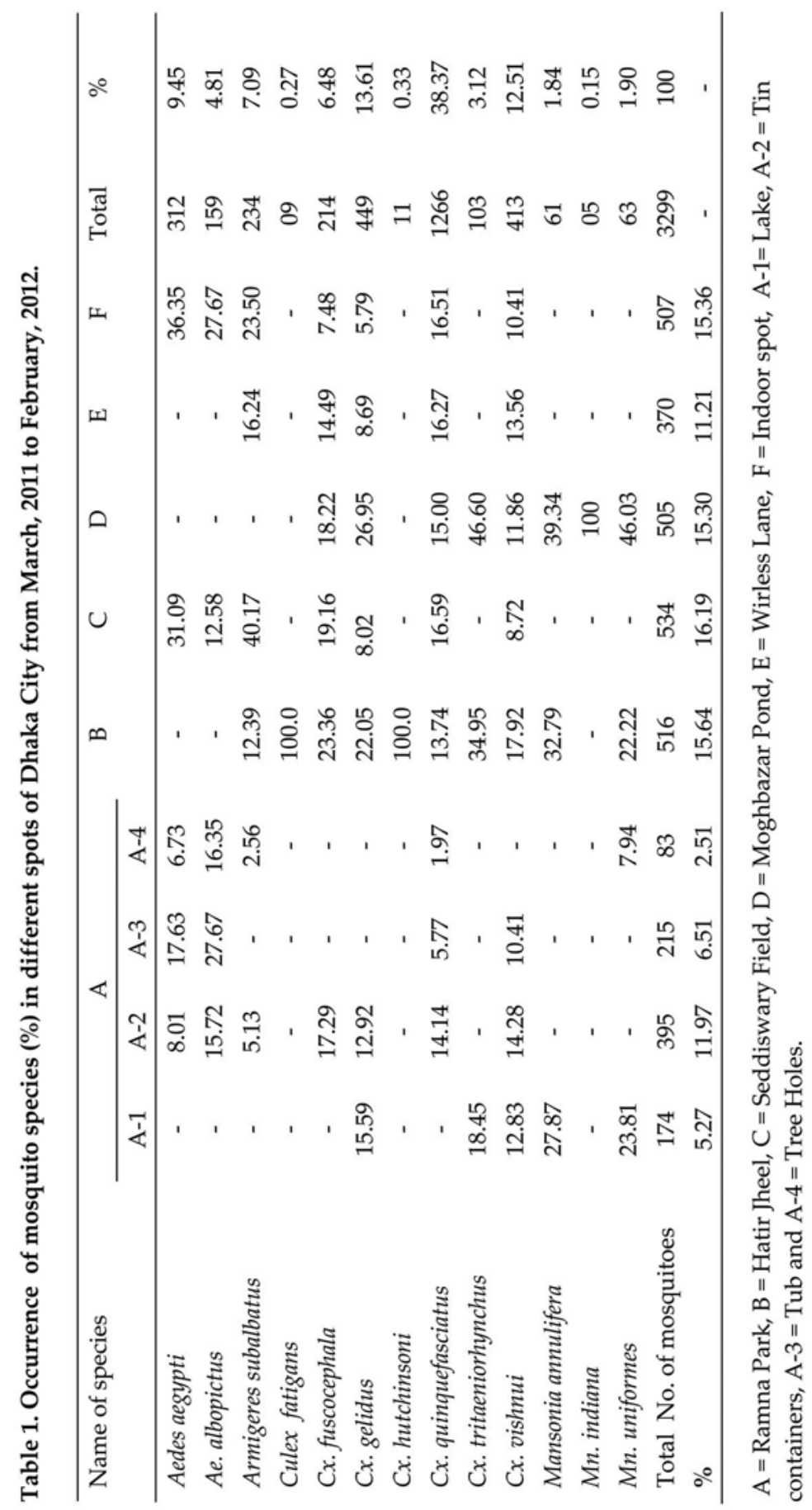


to the genus Culex, 10 to Anopheles, four to Aedes, two to Mansonia, two to Armigeres and one to Ficalbia ${ }^{(12)}$. Farid( ${ }^{(13)}$ and Karim ${ }^{(14)}$ reported 11 and 13 mosquito species, respectively from Dhaka City.

Out of the 13 mosquito species, Cx. quinquefasciatus occupied the highest (38.37\%) and $C x$. gelidus the second highest $(13.61 \%)$ based on the total number collected. Previously Ameen and Moizuddin ${ }^{(15)}$ reported that $C x$. quinquefasciatus was the predominant species because the polluted organic-rich water in mosquito breeding places are comparatively more in Dhaka city and it is still the predominant mosquito species in the city. Farid ${ }^{(13)}$ reported the presence of $25.22 \%$ of $C x$. quinquefasciatus in the City. The peak population density of $C x$. quinquefasciatus was observed in November $(19.19 \%)$ and its lowest population was in July (0.55\%) (Table 2). Farid(13) also reported the highest percentage of $C x$. quinquefasciatus in February and lowest in June and August.

The larvae of $C x$. gelidus were found throughout the year except in January with a peak population in June $(20.50 \%)$ and lowest in December $(0.89 \%)$. These mosquitoes disappeared in the middle of November, just as the dry season approaches(12,15). $C x$. gelidus peaked in number during the monsoon period, but lowest in winter ${ }^{(13,14)}$. Other four species of Culex mosquitoes were present at low population level, some of which were, however, present throughout the year (Table 1). The highest population of $A e$. aegypti was observed in July $(29.17 \%)$ and of Ae albopictus in June (23.27\%). The former species was present throughout the year in the city, whereas the later was absent in December and January (Table 2). The absence of Ae. albopictus in the winter season might be due to the fact that it is not a domestic species like Ae. aegypti, but remain outside house in the garden and open spaces which make them exposed to the extreme weather of winter season and tend to enforce them to undergo diapause when the environment goes beyond tolerance. Out of the three species of Mansonia, two Mn. annulifera and Mn. uniformis were present at 1.84 and $1.90 \%$ density levels, respectively throughout the year except the months of December-February, whereas $M n$. indiana was only present in May and June, and was found only in Mogbazar pond (Tables 1,2). The population density of Ar. subulbatus was $7.09 \%$ (Table 1$)$. The highest number of this species $(25.64 \%)$ was found in February and totally absent in the months of October and November (Table 2).

Species of Aedes were found in domestic habitat, containers and tree holes ${ }^{(16,17)}$. In fresh water lake, five species, e.g. Cx. vishnui, Cx. gelidus, Cx. tritaeniorhynchus, Mn. annulifera and $M n$. unifomis were found, among them $C x$. gelidus occupied the highest number (40.22\%) (Table 3). Cx. gelidus, $C x$. vishnui and $C x$. tritaeniorhynchus, preferred to breed in fresh water pools and natural containers, but they were also found in domestic cemented tanks and ground tanks in adverse season. The larvae of Mansonia were found in fresh water reservoir with vegetation and observed in rainy season(18). $C x$. quinquefasciatus was not observed in the fresh water lake because the larvae of $C x$. quinquefasciatus prefer polluted ground water site like blocked drains, cesspools, shallow 
KHAN et al.

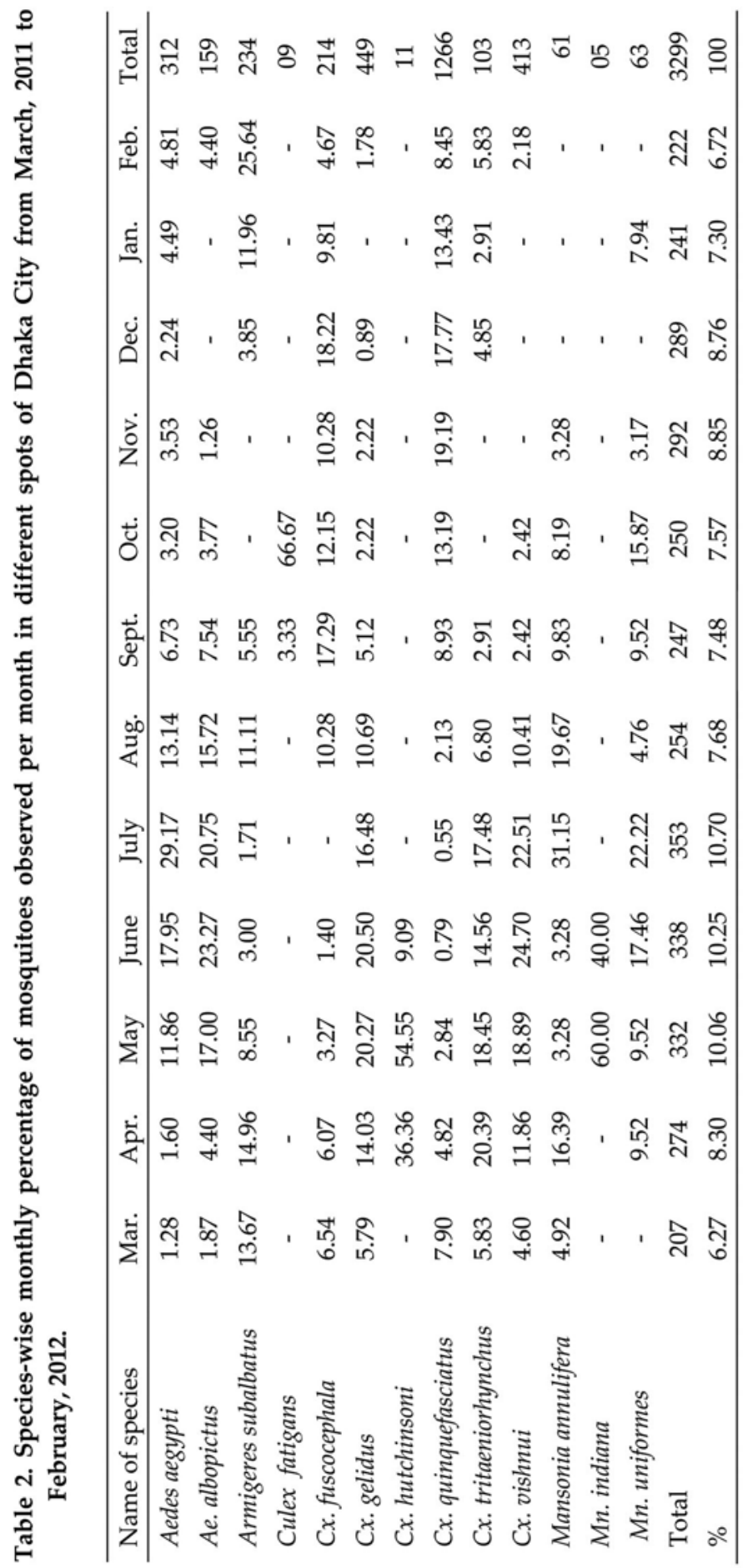


ponds, containers like cemented tank, big jars, tree holes and other polluted water reservoirs ${ }^{(15)}$. In semi-polluted Jheel, all of the identified species were observed, except Ae. aegypti, Ae. albopictus and $M n$. indiana. In semi-polluted pond water, $C x$. quinquefasciatus was found maximum (33.72\%). Cx. fatigans $(1.74 \%)$ and Cx. hutchinsoni $(2.13 \%)$ were only observed in semi-poluted Jheel (Table 4). In Jakarta, the breeding places of $C x$. fatigans were ditches and certain pools with polluted water. $C x$. fatigans and $C x$. hutchinsoni were observed at polluted water reservoir in Dhaka City(14).

In coconut shell, four types of mosquito larvae were found, these were: $C x$. quinquefasciatus, Ar. subalbatus, Cx. fuscocephala and Ae. aegypti (Table 3). In rainy season, coconut shell was full of water with the dirty humus which is preferable for the breeding of $C x$. quinquefasciatus and Ar. subalbatus mosquitoes; Ae. aegypti was observed in less polluted coconut shell. In the tree holes, five species were collected, among them Ae. albopictus occupied the highest in number (31.32\%) (Table 3). In tubs, Cx. quinquefasciatus, $C x$. vishnui, Ae aegypti and Ae. albopictus were found. In polluted drains, $C x$. quinquefasciatus, $C x$. vishnui, $C x$. gelidus were common, but $C x$. quinquefasciatus was the dominant species. In indoor habitat, $C x$. quinquefasciatus and Ae. aegypti were more abundant (Table 3).

The larvae of Ae. aegypti and Ae. albopictus were collected from the flower tubs, fresh water container, tree holes, indoor habitat and were also tires, tin cane and tree holes from outdoor habitat from Ramna Park. In Bangladesh, Ae. aegypti and Ae. albopictus larvae were found mainly in natural containers and indoor habitat in Dhaka city, Srimongal tea garden and Thakurgoan ${ }^{(18)}$. The larvae of Ae. aegypti and Ae. albopictus were found in tin container during rainy season. In monsoon period, the container contains fresh rainy water, so that it was convenient for breeding and larval development of above species. Ae aegypti and Ae. albopictus were observed maximum in rainy season (Table 2). In Dhaka Metropolitan City, Ae. aegypti and Ae. albopictus were found resting and biting in dwelling and at outdoors in rainy month ${ }^{(17,19)}$. The larvae of Ar. subalbatus were found in highly polluted water in different study area. Ar. subalbatus breeds in both natural and artificial containers, bamboo and banana stumps and other peridomestic containers holding strongly polluted water(17).

From the survey it has been apparent that the polluted water bodies in the City, e.g. semi-polluted ponds, lakes, drains, artificial reservoirs harbor most of the mosquitoes. It is therefore, suggestive that concern authority should take necessary steps to control the mosquito species from the polluted and semi-polluted water bodies by adopting an effective integrated mosquito management system in Dhaka Metropolitan City. 
KHAN et al.

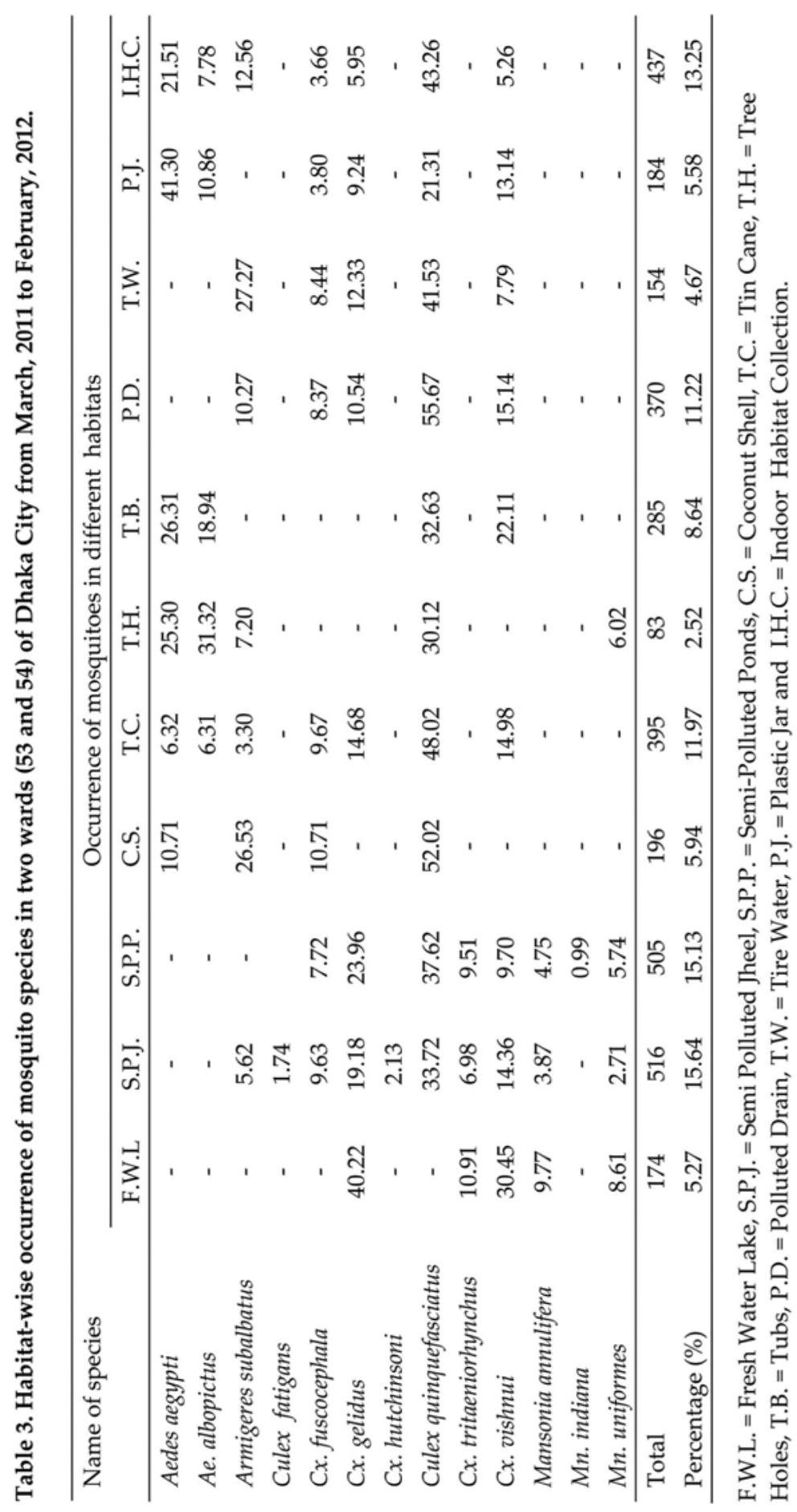




\section{Acknowledgement}

The authors gratefully acknowledge the help and assistance received from Mr. Tauhid Uddin Ahmed, an eminent medical entomologist, in the identification of mosquito species.

\section{References}

1. Harrington, R and SE Nigel 1995. Insects in a changing environment. Academic Press Limited, London. NY. pp. 535.

2. Ahmed TU, BM Nessa and ME Khoda 1987. Seasonal prevalence and filarial infection of Culex quinquefasciatus in Mirpur, Dhaka. Annual Bangladesh Science Conference 12.

3. Ahmed TU 2009. Encyclopedia of flora and fauna of Bangladesh 2009 In: Arthropoda: Insecta3, Volume 21, (Diptera: Culicidae). J. Asiat. Soc. Bangladesh. pp. 225-330.

4. Staples JE, RF Breiman and AM Powers 2009. Epidemiological review of a re-emerging infectious disease. Clinic. Infect. Dis. 49(6): 942-48.

5. Khan AM and TU Ahmed 1986. Dengue status in Bangladesh. Dengue News Letter. Vol. 2 Sea/VBC 29: 1.

6. Mahmood B and S Mahmud 2011. Emergence of Dengue in Bangladesh a major international public health concern in recent years. J. Environ. Res. Manage. 2(3): 35-41.

7. Solomon T, DW Beasley, PM Ekkelenkamp, MJ Cardosa and AD Barret 2003. Origin and evolution of Japanese encephalitis virus in South East Asia. J. Virol. 77: 3091-3098.

8. Huda KMN and Q Banu 1987. Filariasis, Dengue and Japanese Encephalitis and their vectors in Bangladesh. Mosquito Borne Diseases Bulletin 4.

9. Erlanger TE, S Weiss, J Keiser, L Utzinger and K Wiedenmayer 2009. Past, present, and future of Japanese Encephalitis. Emerge. Infect. Diseases 15(1): 32-47.

10. Aldemir A, B Demirci, MA Kippik, B Alten and A Baysal 2009. Species composition and seasonal dynamics of mosquito larvae (Diptera: culicidae) in Igdir plain,Turkey. Kafkas Univ. Vet. Fak. Derg. 15: 103-110.

11. Rueda LM 2004. Pictorial keys for the identification of mosquito associated with dengue virus transmission. Magnolia Press, Auckland New Zealand. Zootaxa 589: 1-60.

12. Ameen M and M Moizuddin 1973. Bionomics of the common mosquitoes of Dacca. J. Nat. His. 7: $1-21$.

13. Farid S. 2012. Study on the seasonal fluctuation of various species of mosquito in Dhaka City. MS Thesis, Department of Zoology, University of Dhaka. pp. 25-52.

14. Karim R. 2012. Seasonal fluctuation of mosquito in Dhaka City. MS Thesis, Department of Zoology, University of Dhaka. pp. 34-62.

15. Ameen M and M Moizuddin 1973. Duration of the various developmental stages of Culex pipiens fatigans Wiedemann (Diptera: Culicidae) in Dacca City. Bangladesh J. Zool. 1: $11-12$. 
16. Dolo G, OJ Briet, A Dao, SF Traore, M Bouare, N Sogoba, O Niare, M Bagayogo, D Sangare, $\mathrm{T}$ Teuscher and YT Toure. 2004. Malaria transmission in relation to rice cultivation in the irrigated Sahel of Mali. Acta. Trop. 89(2): 147-159.

17. Ahmed TU, GP Joshi, RU Ahmed, ZU Dewan, MS Chowdhury and S Akter 1990. Container habitat mosquitoes of Bangladesh. Bangladesh J. Zool. 5: 6-18.

18. Ahmed TU, KN Jannat, RU Akhter, S Ahmed, ZU Dewan and ME Khoda 2004. Studies on mosquitoes of Thakurgoan district in Bangladesh. Bangladesh J. Entomol. 14(1): 47-62.

19. Hossain MI, Y Wagatsuma, M Chowdhury, TU Ahmed and MA Uddin and SMN Sohel 2000. Analysis of socio demographic factors related to DF/DHF outbreak in Dhaka city. Dengue Bull. 24: 2

(Manuscript received on 18 June, 2013; revised on 2 September, 2013) 